\title{
Cycling and the middle-aged man: More urodynamics than aerodynamics?
}

$\mathrm{L}$ ast summer, for the third year in a row, more than 4000 people (mostly middle-aged men) pedalled their road bikes from downtown Vancouver to Whistler, BC, a whopping $122 \mathrm{~km}$, uphill. If anything, the Whistler GranFondo (Italian for "big ride") is evidence that cycling is soaring in popularity and a sure cure for the middle-aged man's need for speed, social contact and exercise. Road riding is the fastest growing group sport for 40- to 60-year-old men, a groove where the economics of middle age fit, almost perfectly, with the tempo and limits of middle-aged bodies.

Cycling's accelerating popularity is easy to explain. Many men who are approaching their forties, and who were physically active in their younger years (playing soccer and hockey, running marathons and running after kids), develop nagging joint or other musculoskeletal problems, but they still have their mojo and want to run with the pack. They just need a new pack. It helps that by the time the body is wearing down and the kids are growing up, there is a bit of extra cash in the wallet. This demographic doesn't get too winded by plunking down $\$ 4000$ or so for a decent carbon-fibre bike, and more money still for a cycling computer to collect, store and post personal cycling data and a closet full of tight, ridiculously coloured cycling apparel.

But if we middle-aged men think high-speed cycling and colourful lycra are harmless, we need to ask ourselves one question: Are we ready for the urodynamic changes that await us?

An innocent question, right?

We've all heard rumours of rampant impotence spreading through the peloton like a nasty virus, but are the adverse effects of this sport really so hazardous to our nether regions? According to a very reliable source of information (the pharmaceutical industry), a surprising number of men in our demographic suffer from low testosterone, premature ejaculation

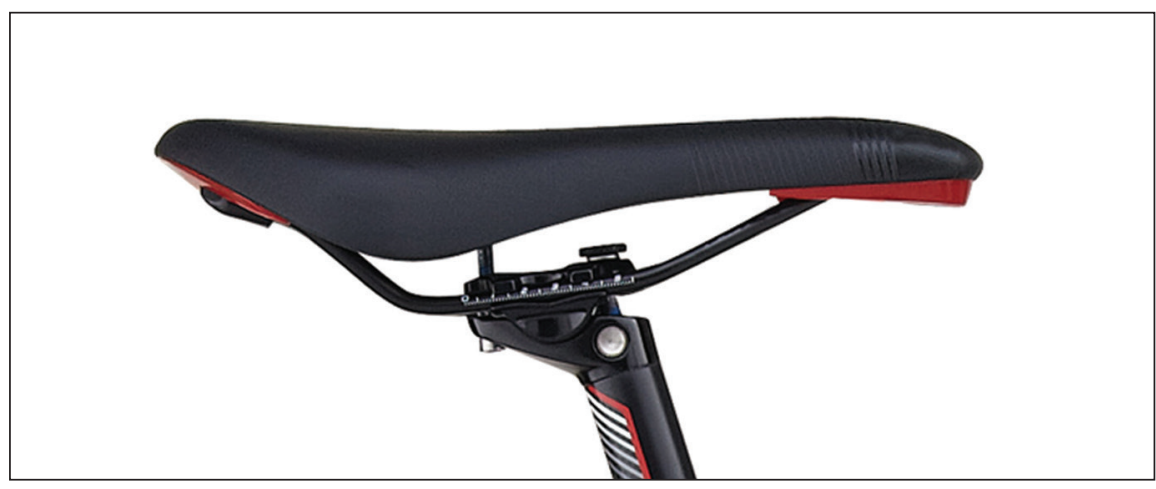

and erectile dysfunction, so being perched on bikes for hours on end, attacking hills with our buddies, may only be adding to our toll of "urowoes."

All the sitting is actually a godsend (made easier by a featherweight $\$ 150$ seat that cradles your prostate like a baby in a hammock) because compared with the pounding of feet on pavement, pushing pedals is relatively forgiving to slowly deteriorating hips, knees and Achilles heels.

You might intuit that Newton's third law must have a say in all this: might the "action" of pedalling for hours on end create a new batch of "reactions," including prostatitis, hemorrhoids, urinary leakage and saddle sores? Well, according to one study, "bicycle riding as exercise or hobby has no negative effect on LUTS (Lower Urinary Tract Symptoms) and erectile function" in healthy men.

But, let me point out that the operative words in this study are "exercise or hobby," because different effects are seen if you study "bicycle riding as obsession." Research has shown that the overly fixated will tend to see more adverse effects in their personal relationships and their gluteal regions, especially near the buttock cheek that holds the wallet.

Relationships may suffer when men spend precious weekend hours on crazily long rides, and on the mandatory postride caffeinated debriefings. Then there's the whining; the most common complaint being how heavy the bike is. The cyclist's obsessive search for featherweight cycling components can present itself as both pathological and expensive. Nothing on God's green earth is more important to the middle-aged man who is new to road cycling than spending money on bike parts that are so light his bike will float up mountains by itself.

By way of example, let's look at a particular German-engineered, überlightweight water-bottle cage. A mere $18 \mathrm{~g}$, this little bit of cycling slickness is one of the lightest water-bottle cages in the world. And the price? Weighing in at around $65 €$ (about \$95CAD), it is only $21 \mathrm{~g}$ lighter than a plastic bottle holder that you can get for $\$ 5$.

Are these things worth it? Well, that's for the man and his new obsession to decide. Paying all that money for super-light bike parts may not make you lighter or faster, but we all know how good it feels to try, even if it only lightens your wallet.

Happy riding.

\section{Alan Cassels BA MPA}

Faculty of Human and Social Development University of Victoria

Victoria, BC

\section{Reference}

1. Baek S, Lee SY, Kim JM, et al. Bicycle riding: impact on lower urinary tract symptoms and erectile function in healthy men. Int Neurourol J 2011; 15:97-101.

CMAJ 2014. DOI:10.1503/cmaj.131789

All editorial matter in CMAJ represents the opinions of the authors and not necessarily those of the Canadian Medical Association. 